\title{
Long-term outcomes of synchronous splenectomy and hepatectomy or radiofrequency ablation for hepatocellular carcinoma and esophagogastric variceal bleeding
}

\section{Jia-li Ma}

Capital Medical University

\section{Li Jiang}

Capital Medical University

\section{Ping Li}

Capital Medical University

Ling-ling $\mathrm{He}$

Capital Medical University

Hong-shan Wei ( $\square$ drwei@ccmu.edu.cn )

Capital Medical University

\section{Research Article}

Keywords: hepatocellular carcinoma, esophagogastric variceal bleeding, synchronous splenectomy, hepatectomy, radiofrequency ablation

Posted Date: April 20th, 2021

DOI: https://doi.org/10.21203/rs.3.rs-367796/v1

License: (c) (i) This work is licensed under a Creative Commons Attribution 4.0 International License.

Read Full License 


\section{Abstract}

Aim: This study aimed to compare the long-term outcomes of hepatectomy and radiofrequency ablation (RFA) combined with pericardial devascularization (PCDV) plus splenectomy for patients with cirrhosis having hepatocellular carcinoma and esophagogastric variceal bleeding.

Materials and Methods: Between October 2008 and March 2018, 46 patients with cirrhosis having hepatocellular carcinoma and esophagogastric variceal bleeding for portal hypertension were included in this study. The overall survival curves, recurrence-free survival curves, and rebleeding-free survival curves were plotted using Kaplan-Meier analysis. The log-rank test was used to compare time-to-event curves between groups.

Results: The median follow-up time was 38 months. Among 20 patients undergoing RFA, the 1-, 3-, and 5year overall survival rates were $95.00 \%, 60.00 \%$, and $35.00 \%$, respectively. The $1-, 3$ - and 5 -year recurrencefree survival rates were $35.00 \%, 25.00 \%$, and $10.00 \%$, respectively. The 1,3- and 5-year rebleeding-free survival rates were $85.00 \%, 60.00 \%$, and $40.00 \%$, respectively. Among 26 patients undergoing hepatectomy, the 1-, 3-, and 5-year overall survival rates were $96.15 \%, 50.00 \%$, and $34.62 \%$, respectively. The 1-, 3-, and 5-year recurrence-free survival rates were $65.38 \%, 19.23 \%$, and $11.54 \%$, respectively. The 1-, 3 -, and 5-year rebleeding-free survival rates were $73.08 \%, 42.31 \%$, and $26.92 \%$, respectively. No significant differences were found in overall, recurrence-free, and rebleeding-free survival rates.

Conclusions: Hepatectomy or RFA with PCDV plus splenectomy might be a safe and effective treatment for patients with cirrhosis having hepatocellular carcinoma and esophagogastric variceal bleeding. "Hepatectomy first" strategy may be considered due to its lower and later recurrence. More attention should be paid to background liver diseases after surgery.

\section{Introduction}

Hepatocellular carcinoma (HCC) is the sixth most commonly diagnosed cancer and the fourth cause of cancer-related death worldwide, accounting for 841,000 new cases and 782,000 deaths annually ${ }^{1}$. Surgical resection is the first choice of treatment for HCC, which has been recommended as the primary treatment for solitary hepatocellular cancer with Child's A stage and normal bilirubin level, and without significant portal hypertension ${ }^{2,3}$. The indication for hepatectomy has expanded with the improvement in surgical techniques and perioperative management ${ }^{4}$. A previous study suggested that portal hypertension should not be considered as the absolute contraindication ${ }^{5}$. Hepatectomy is one of the treatment choices for patients with Child's A and B early-stage tumor ${ }^{6}$. Radiofrequency ablation (RFA) is a minimally invasive therapy for HCC, with the advantages of ease of use, less invasiveness, good efficacy, and relatively low cost. It may have equivalent efficacy of resection for tumors with a diameter $\leq 3 \mathrm{~cm}^{7}, 8$. RFA ablates the whole tumor while minimizing the damage to nontumor tissues. Covering the range of tumor infiltration and satellite lesions at the same time, it is also one of the curative modalities for HCC. 
Cirrhosis is the most predisposing factor for HCC. Approximately $80 \%$ of HCCs develop in patients with cirrhosis $^{9}$. Esophagogastric variceal bleeding (EVB) is a common complication in patients with HCC. The incidence of patients with HCC presenting with EVB ranges from $1 \%$ to $15 \%{ }^{10}$. Tumor infiltration can aggravate portal hypertension, resulting in the development of collateral circulation and esophagogastric varices. HCC is one of several factors associated with increased mortality for an episode of variceal bleeding.

In China, for most cirrhotic patients with variceal bleeding, the available treatment is endoscopic therapy, surgery and interventional therapies. Interventional therapies such as TIPS, might best serve as a bridge to liver transplantation for patients with refractory variceal bleeding, but, timely liver transplantation is often not available and the cost of TIPS is significant. Pericardial devascularization (PCDV) plus splenectomy is widely used to treat patients with variceal bleeding. For patients with Child's A or B stage, PCDV is not inferior to TIPS in terms of treating portal hypertension and recurrent variceal bleeding and preventing rebleeding ${ }^{11}$, which is a safe and effective treatment ${ }^{12}$.

Meanwhile, studies indicated that splenectomy combined with hepatectomy could extend disease-free survival and overall survival ${ }^{13,14}$. Hepatectomy or ablation combined with splenectomy is a safe treatment in selected patients with HCC. It shows acceptable mortality and complications and favorable survival benefits ${ }^{15}$.

The prognostic impacts of hepatectomy or RFA combined with PCDV and splenectomy have rarely been explored. The present study aimed to compare the clinical outcomes of RFA and hepatectomy plus PCDV and splenectomy. The findings might help determine appropriate treatment choices for patients with cirrhosis having HCC and EVB.

\section{Materials And Methods}

\section{Patients}

Between October 2008 and March 2018, 426 patients with cirrhosis underwent PCDV plus splenectomy in our medical center. Further, 46 eligible patients diagnosed with both HCC and EVB for portal hypertension were included in this retrospective study. The exclusion criteria were as follows: (i) patients with other serious concurrent illnesses expected to decrease expectancy; (ii) patients who received both the treatments (RFA and hepatectomy) for HCC; and (iii) patients who were found to have extrahepatic metastasis and/or macroscopic vascular invasion on preoperative examinations (ultrasonography, enhanced computed tomography, and magnetic resonance imaging). HCC diagnosis was based on AASLD or Chinese criteria $8,{ }^{16}$ or histology. Further, 26 patients underwent hepatectomy combined with PCDV plus splenectomy, and 20 patients underwent RFA combined with PCDV plus splenectomy.

The study was approved by the ethics committee of Beijing Ditan Hospital, Capital Medical University. All patients signed informed consent before treatments. All the data of this study come from the research 
which registered in the Chinese Clinical Trial Registry (2/11/2018, ChiCTR1800019265, all the data were available on http://www.chictr.org.cn/showproj.aspx?proj=32565). Details of the trail is provided in the research protocol.

\section{Preoperative assessments}

The data on baseline characteristics were collected prior to surgery, including clinical characteristics and laboratory values, such as white blood cell count, red blood cell count, platelet count, lymphocyte count, neutrophilic granulocyte percentage, hemoglobin content, alanine aminotransferase level, aspartate transferase level, gamma-glutamyl transpeptidase level, cholinesterase level, total bilirubin level, albumin level, creatinine level, prothrombin time, alpha-fetoprotein (AFP) level, and so on. Trans-abdominal ultrasonography values, such as portal vein diameter and spleen thickness, were also determined. ChildPugh score and BCLC stage were recorded. All patients underwent an endoscopic examination before surgery.

\section{Surgical and RFA treatments}

Conventional open surgery was performed in all patients, including curative wedge hepatectomy and PCDV plus splenectomy. PCDV and splenectomy were performed as previously described. Briefly, the gastric and esophageal branches of the gastric coronary vein were disconnected after the routine splenectomy. The esophageal branch was disconnected and ligated. Then, the gastric posterior vein and the left subphrenic vein were ligated. Finally, arteries accompanied by the veins (including the left gastric artery, left gastroepiploic artery, gastric posterior artery, and left subphrenic artery) were disconnected, as previously reported ${ }^{17,18}$. Daily injection of low-molecular-weight heparin over the first week after surgery and oral administration of aspirin for 4 weeks were performed for prophylactic anticoagulation to prevent portal and splenic vein thrombosis.

RFA and hepatectomy were performed under the Chinese criteria: a single HCC smaller than $5 \mathrm{~cm}$ or no more than three tumor nodules, each smaller than $3 \mathrm{~cm}$ in diameter. Curative hepatectomy was defined as the complete removal of all gross lesions of tumor-free margins. The diagnosis of HCC was confirmed after the review of a senior pathologist. RFA was performed by the open or percutaneous approach, immediately before or after PCDV plus splenectomy. Dynamic enhanced CT and/or MRI were used to assess the response about 1 month after the therapy. Repeated ablation therapy was used for patients with a residual tumor. Patients were followed up after a complete response was achieved. Patients were free to choose the treatment option they preferred.

All methods were performed in accordance with the relevant guidelines and regulations.

\section{Follow-up evaluations}

The follow-up was initiated after discharge from the hospital. Routine blood count, liver and kidney functions, AFP, and dynamic contrast-enhanced CT or MRI were performed on all of the patients in the 
first month after the surgery, and then every 3 or 6 months based on the CT/MRI and AFP. An endoscopic examination was performed every 6 months. The follow-up ended at patients' death or in May 2020. Perioperative mortality or complication was defined as death or complication occurring within 1 month after the surgery. The primary end-point was death. The second end-point was 3- and 5-year survival.

\section{Statistical analysis}

Statistically analyses were performed using SPSS 19.0 (IBM Corp., NY, United States). Quantitative data with normal distribution were analyzed using the Student $t$-test. Data without normal distribution were analyzed using the Mann-Whitney $U$ test. Qualitative data were analyzed using the $\chi 2$-test. Univariate survival analysis was performed using Kaplan-Meier statistical analysis. Time-to-event curves between different groups were compared using the log-rank test. The significance levels were set to Two-sided $P$ values $<0.05$.

Recurrence-free survival was calculated from the day of surgery to the day of any recurrence or death due to any cause. If recurrence did not occur, patients were censored on the date of death or the last followup.

\section{Results}

\section{Baseline characteristics}

The characteristics of 46 patients 38 male and 8 female, with an average age of $50.48 \pm 8.47$ years (range: 34-68 years)] were investigated; 20 underwent RFA and simultaneous PCDV plus splenectomy, while the remaining 26 underwent hepatectomy and PCDV plus splenectomy. The demographic and clinical characteristics of the patients are shown in Table 1. The amount of blood loss and intraoperative blood transfusion was higher in the hepatectomy group. However, the tumor size, differentiation status, surgery time, Child's score, and so on did not differ between the RFA and hepatectomy groups.

\section{Perioperative complications}

No one died within a month after the surgery in both groups. The overall incidence of perioperative complications was $26.09 \%$. The perioperative complication in the RFA group was portal vein thrombosis (PVT) (4); the complications in the hepatectomy group were PVT (6), intra-abdominal bleeding (1), and pulmonary infection (1). No significant difference in complications was found between the two groups ( $\left.c^{2}=0.68, P=0.41\right)$. Two patients in the RFA group compared with four patients in the hepatectomy group suffered from esophagogastric variceal rebleeding during the follow-up time $\left(c^{2}=0.289, P=0.684\right)$.

\section{Tumor recurrence and survival analysis}

The median follow-up time was 38 months (range: 12-129 months). No difference was found in the rate of rebleeding $\left(c^{2}=0.289, P=0.684\right)$, but the recurrence rate seemed to be lower in the hepatectomy group $\left(c^{2}=4.182, P=0.041\right)$. 
Among the 20 patients undergoing RFA, 13 experienced recurrence or metastasis, 2 suffered from variceal rebleeding, and 3 died. The 1-, 3- and 5-year overall survival rate was $95.00 \%, 60.00 \%$, and $35.00 \%$, respectively. The 1, 3- and 5-year recurrence-free survival rate was $35.00 \%, 25.00 \%$, and $10.00 \%$, respectively. The 1-, 3-, and 5-year rebleeding-free survival rate was $85.00 \%, 60.00 \%$, and $40.00 \%$, respectively.

Among 26 patients undergoing hepatectomy, 9 experienced recurrence or metastasis, 4 suffered from variceal rebleeding, and 4 died. The 1-, 3-, and 5-year overall survival rate was $96.15 \%, 50.00 \%$, and $34.62 \%$, respectively. The 1-, 3- and 5-year recurrence-free survival rate was $65.38 \%, 19.23 \%$, and $11.54 \%$, respectively. The 1-, 3-, and 5-year rebleeding-free survival rate was $73.08 \%, 42.31 \%$, and $26.92 \%$, respectively. No significant difference was observed between the two groups in terms of overall, recurrence-free, and rebleeding survival rates (Fig. A, B, and C).

The RFA and hepatectomy groups comprised 7 and 15 recurrence-rebleeding-free patients. The survival rate in recurrence-rebleeding-positive and recurrence-rebleeding-free groups was similar $(P=0.225$, Fig. $D)$. Four patients died in the recurrence-rebleeding-free group; all of them were HBsAg-positive and/or HBV DNA-positive men aged more than 40 years and died of liver failure.

\section{Discussion}

Patients with cirrhosis having HCC and EVB are difficult to treat with monotherapy. The tumor, hepatic function, and secondary prevention of variceal bleeding should all be considered in the therapeutic schedule. The present study showed that RFA/hepatectomy combined with PCDV plus splenectomy had similar effects on tumor recurrence control, rebleeding control, and overall survival for patients with cirrhosis having HCC and EVB. No patient died during the perioperative period in both groups. The perioperative complications were similar, too. PVT was the major complication.

Liver resection plus Hassab's operation could be safely performed in selected patients with HCC and EVB. Concomitant Hassab's operation improves the long-term prognosis ${ }^{19}$. PCDV plus splenectomy is an effective and simple method for hemostasis and widely used in China. EVB, thrombocytopenia, and/or leukopenia can be resolved at the same time ${ }^{20}$, without the disadvantage of hepatic encephalopathy ${ }^{21}$. The combination of splenectomy and PCDV decreased portal pressure ${ }^{22}$ and led to a consequent decrease in the severity of varices ${ }^{23,24}$.

Surgical treatment is the most important and best treatment choice for patients with HCC. Hepatectomy is a curative approach, especially in stage $\mathrm{la}, \mathrm{lb}$, and lla patients. However, patients suitable for hepatectomy are limited. Hepatic failure is often seen in patients after the resection of excessive liver volume. Patients even showed good hepatic reserve function before the surgery, and the 5-year recurrence and metastasis rate after hepatectomy was up to $40 \%-70 \%{ }^{8}$. RFA provided a curative outcome in earlystage patients and had a comparable survival rate as hepatectomy. Studies demonstrated that the recurrence rate was similar after the two treatment modalities ${ }^{25}$. The 1-, 2-, and 3-year recurrence rates 
were $10.7 \%, 18.4 \%$, and $24.6 \%$, respectively, in 65 patients of the resection group, and $8.5 \%, 19.1 \%$, and $23.4 \%$, respectively, in 47 patients in the RFA group ${ }^{18}$. However, other studies showed that the disease-free survival and recurrence-free survival rates were better in the hepatectomy group than in the RFA group. The clinical outcomes of RFA were not comparable to those of surgery $26,27,28$. In the present study, the 1-, $2-$, and 3 -year recurrence rates were $0 \%, 19.23 \%$, and $23.08 \%$, respectively, in resection group and $15.00 \%$, $30.00 \%$, and $45.00 \%$, respectively, in the RFA group. The same trend of lower recurrence rate was observed after hepatectomy compared with RFA. Early recurrence seemed more often in the RFA group, and late recurrence occurred more in the resection group. Early recurrence was generally associated with tumorrelated factors. It was hard to distinguish minimal tumor residual from recurrence among patients with early recurrence in the RFA group. However, late recurrence might be due to de novo chronic liver disease, considering viral loads, baseline HBsAg level, inflammation activity, and fibrosis degree ${ }^{29,30}$. All laterecurrence patients (recurrence-free period $\geq 3$ years) in the present study had the baseline HBsAg level of $\geq 250 \mathrm{IU} / \mathrm{mL}$.

Some studies showed that the overall survival in the RFA and surgical resection groups was the same $18,31,32$. The 1 -year overall survival was more than $90 \%$, the 2 -year overall survival was about $80 \%-$ $90 \%$, but the 3 -year overall survival was $60 \%-80 \%$. The low survival was likely due to the hepatic insufficiency and tumor recurrence. Studies enrolling patients with better liver function (Child's A) and smaller and single tumors showed better long-term survival rate. In the present study, the 3-year overall survival was lower (50\%-60\%) than previously reported, especially in the hepatectomy group. However, only one patient died of variceal bleeding, two of tumor recurrences, and the other four of liver failure. Severe portal hypertension was not the main reason of high mortality in the present study; deterioration of liver function might be the reason.

A previous study included 203 patients undergoing open splenectomy and esophagogastric devascularization. Three patients had variceal rebleeding during the perioperative period, and seven patients rebled during the follow-up period. The total rebleeding rate was $4.93 \%{ }^{33}$. Another retrospective study retrieved 283 patients with Child's A or B class cirrhosis with portal hypertension and recurrent variceal bleeding. The perioperative rebleeding rate was $3.2 \%$, and the total rebleeding rate during the follow-up period (29 months) was $4.6 \%{ }^{34}$. In the present study, no one rebled during the perioperative period, but 6 of 46 patients had variceal rebleeding during the follow-up period ( 2 in the RFA group and 4 in the hepatectomy group). The rebleeding rate was $13.04 \%$, much higher than that reported in previous studies. The complication PVT should not be the main cause of rebleeding because only one of six patients who rebled had PVT and a much longer follow-up time (12-129 months vs 4-75 months), hepatectomy might cause secondary portal hypertension ${ }^{35}$, and tumor infiltration might aggravate portal hypertension ${ }^{36}$.

Seven patients died during the follow-up period; two died of HCC, one died of EVB, and the other four recurrence-rebleeding-free patients died of liver failure (HBsAg-positive and/or HBV DNA-positive men aged more than 40 years). HBsAg-positive and/or HBV DNA-positive adults were at high risk of $\mathrm{HCC}^{37}$. 
Older age and ongoing HBV replication with persistent or intermittent detection of HBV DNA have been found to be related to cirrhosis progression ${ }^{38}$. An EUROGEP cohort study found a linear and slow increase in the incidence rate of $\mathrm{HCC}$, hepatic decompensation, and liver-related death in HBsAg-positive patients; the most common cause of death or liver transplantation in these patients was liver failure (53\%), compared with HCC (35\%) and non-hepatic causes $(12 \%)^{39}$. Active HBV replication was considered to be a negative prognostic factor ${ }^{40,41}$. The 5-year survival rate of HBV-DNA-positive patients was much lower than that of HBeAg-negative/HBV-negative patients with compensated cirrhosis $(79 \%$ vs $86 \%$ vs $97 \%, P=$ $0.01)^{33}$. The risk of decompensation and mortality was 4.0-fold and 5.9-fold in DNA-negative patients ${ }^{33}$. The variceal bleeding and HCC might be cured by synchronous splenectomy and hepatectomy or RFA, but decompensation persisted. Hepatitis B virus could be reactivated in patients with $\mathrm{HCC}$ undergoing hepatectomy or RFA ${ }^{42}$. Hepatic blood inflow occlusion during hepatectomy might influence postoperative liver regeneration ${ }^{43}$. The reactivation of virus, reduction of blood supply to the liver, and the loss of functioning liver parenchyma all contributed to liver failure.

This study had some limitations. First, the data were obtained from a single center, and the study had small sample size. A multicenter study with more patients should be performed to draw a more conclusive statistical statement. Second, the retrospective design of the study suffered from different degrees of bias; differences in patients' baseline status might influence the clinical outcomes. Third, very few patients had a moderate-to-severe impaired liver function; the safety and effectiveness in these patients should be validated.

In conclusion, hepatectomy or RFA with simultaneous PCDV plus splenectomy might be a safe and effective treatment choice for patients with cirrhosis having hepatocellular carcinoma and EVB. A trend of lower recurrence rate was observed after hepatectomy compared with RFA combined with PCDV. "Hepatectomy first" strategy may be considered for enlisting liver transplantation or other appropriate salvage treatments for patients at high risk for recurrence. We should pay more attention to the background liver diseases, besides variceal rebleeding and tumor recurrence.

\section{Abbreviations}

ALT, alanine aminotransferase

AST, aspartate transferase

ALB, albumin

AFP, alpha-fetoprotein

CHE, cholinesterase

$\mathrm{Cr}$, creatinine 
EVB, esophagogastric variceal bleeding

GGT, gamma-glutamyl transpeptidase

HCC, hepatocellular carcinoma

HGB, hemoglobin

LYM, lymphocyte

NEU\%, neutrophilic granulocyte percentage

PCDV, pericardial devascularization

PLT, platelet

PT, prothrombin time

PVT, portal vein thrombosis

RFA, radiofrequency ablation

$\mathrm{RBC}$, red blood cell

TBIL, total bilirubin

WBC, white blood cell

\section{Declarations}

\section{Ethics approval and consent to participate}

Our retrospective study was approved by the Clinical Ethics Committees of Beijing Ditan Hospital, Capital Medical University (JDLKZ2018-021-01). All Patients provided written informed consents in accordance with the Declaration of Helsinki.

\section{Competing interests}

The authors declare that they have no competing interests. Copyright transfer, authorship responsibility and Conflict of Interest were signed by all authors

All authors had access to the study data and had reviewed and approved the final manuscript.

\section{Funding}

Grants to conduct this study were provided by the Science Foundation of Capital Medicine Development (2014-2-2171); Capital Foundation for Clinical Characteristic Applied Research Projects 
(Z141107002514132) and Capital Foundation for Clinical Characteristic Applied Research

Projects(Z181100001718084); The Digestive Medical Coordinated Development Center of Beijing Hospitals Authority (XXZ0404) to Prof. Wei. Capital Medical University Affiliated Beijing Ditan Hospital Young Talent Development Fund "Sprout" Project (DTMY201807) to Doc. Ma.

Authors' contributions

WH designed the present study; MJ and JL collected the clinical data; MJ, JL, HL and LP performed statistical analysis; MJ was a major contributor in writing the manuscript. All authors read and approved the final manuscript.

Consent for publication

Not applicable.

Availability of data and materials

The study has been registered in Chinese Clinical Trial Registry (ChiCTR1800019265).

Acknowledgements

We acknowledge Dr. Rong He for helping statistics data, and other colleagues for clinical data collection.

\section{References}

1 Bray F, Ferlay J, Soerjomataram I, Siegel RL, Torre LA, Jemal A. Global cancer statistics 2018: GLOBOCAN estimates of incidence and mortality worldwide for 36 cancers in 185 countries. CA Cancer $J$ Clin. 2018;68(6):394-424.

2 Bruix J, Sherman M; Practice Guidelines Committee, American Association for the Study of Liver Diseases. Management of hepatocellular carcinoma. Hepatology. 2005; 429(5):1208-1236.

3 European Association For The Study Of The Liver, European Organisation For Research And Treatment Of Cancer. EASL-EORTC clinical practice guidelines: management of hepatocellular carcinoma. J Hepatol.2012;56:908-943.

4 Roayaie S, Jibara G, Tabrizian P, Park JW, Yang J, Yan L, Schwartz M, Han G, Izzo F, Chen M, Blanc JF, Johnson P, Kudo M, Roberts LR, Sherman M. The role of hepatic resection in the treatment of hepatocellular cancer. Hepatology. 2015;62(2):440-451.

5 Capussotti L, Ferrero A, Viganò L, Muratore A, Polastri R, Bouzari H. Portal hypertension: contraindication to liver surgery? World J Surg. 2006;30(6):992-999.

6 Kawano Y, Sasaki A, Kai S, Endo Y, Iwaki K, Uchida H, Shibata K, Ohta M, Kitano S. Short and longterm outcomes after hepatic resection for hepatocellular carcinoma withconcomitant esophageal varices 
in patients with cirrhosis. Ann Surg Oncol. 2008;15(6):1670-1676.

7 Chen MS, Li JQ, Zheng Y, Guo RP, Liang HH, Zhang YQ, Lin XJ, Lau WY. A prospective randomized trial comparing percutaneous local ablative therapy and partial hepatectomy for small hepatocellular carcinoma. Ann Surg.2006; 243(3): 321-328.

8 Zhou J, Sun HC, Wang Z, Cong WM, Wang JH, Zeng MS, Yang JM, Bie P, Liu LX, Wen TF, Han GH, Wang MQ, Liu RB, Lu LG, Ren ZG, Chen MS, Zeng ZC, Liang P, Liang CH, Chen M, Yan FH, Wang WP, Ji Y, Cheng WW, Dai CL, Jia WD, Li YM, Li YX, Liang J, Liu TS, Lv GY, Mao YL, Ren WX, Shi HC, Wang WT, Wang XY, Xing BC, Xu JM, Yang JY, Yang YF, Ye SL, Yin ZY, Zhang BH, Zhang SJ, Zhou WP, Zhu JY, Liu R, Shi YH, Xiao YS, Dai Z, Teng GJ, Cai JQ, Wang WL, Dong JH, Li Q, Shen F, Qin SK, Fan J. Guidelines for Diagnosis and Treatment of Primary Liver Cancer in China (2017 Edition). Liver Cancer. 2018;7(3):235-260.

9 Coskun M. Hepatocellular Carcinoma in the Cirrhotic Liver: Evaluation Using Computed Tomography and Magnetic Resonance Imaging. Exp Clin Transplant. 2017;15(Suppl 2):36-44.

10 Kerdsuknirun J, Vilaichone V, Vilaichone RK. Clinical Outcome and Predictive Factors of Variceal Bleeding in Patients with Hepatocellular Carcinoma in Thailand. Asian Pac J Cancer Prev. 2018;19(11):3301-3305.

11 Su AP, Zhang ZD, Tian BL, Zhu JQ. Transjugular intrahepatic portosystemic shunt versus open splenectomy and esophagogastric devascularization for portal hypertension with recurrent variceal bleeding. Hepatobiliary Pancreat Dis Int. 2017;16(2):169-175.

12 Lin J, Liu Q, Liang Z, He W, Chen J, Ma J, Gu C, Wang W. Laparoscopic selective esophagogastric devascularization and splenectomy for patients with cirrhotic portal hypertension. Wideochir Inne Tech Maloinwazyjne. 2019;14(2):187-194.

13 Chen XP, Wu ZD, Huang ZY, Qiu FZ. Use of hepatectomy and

splenectomy to treat hepatocellular carcinoma with cirrhotic

hypersplenism. Br J Surg 2005; 92(3): 334-339.

14 Li W, Shen SQ, Wu SM, Chen ZB, Hu C, Yan RC. Simultaneous hepatectomy and splenectomy versus hepatectomy alone for hepatocellular carcinoma complicated by hypersplenism: a meta-analysis. Onco Targets Ther. 2015; 8:2129-2137.

15 Pei Y, Zhang Z, Mba'nbo-Koumpa AA, Chen X, Zhang W. Improved survival following splenectomy combined with curative treatments for hepatocellular carcinoma in Child $B$ patients: A propensity score matching study. Hepatol Res. 2019;49(2):177-188.

16 Bruix J, Sherman M; Practice Guidelines Committee, American Association for the Study of Liver Diseases. Management of hepatocellular carcinoma. Hepatology. 2005;42(5):1208-1236. 
17 Sun YW, Chen W, Luo M, Hua R, Liu W, Huo YM, Wu ZY, Cao H. Evaluation of surgical procedure selection based on intraoperative free portal pressure measurement in patients with portal hypertension. Hepatobiliary Pancreat Dis Int. 2010;9(3):269-274.

18 Longci Sun, Hong Zhou, Lei Gu, Chunhui Jiang, Ye Liu, Qing Xu. Effects of surgical procedures on the occurrence and development of postoperative portal vein thrombosis in patients with cirrhosis complicated by portal hypertension. Int J Surg. 2015; 16(ptA):31-35.

19 Yang T, He H, Yuan J, Zhang J, Lu J, Lau WY, Yang G, Shen Y, Wang Z, Alshebeeb K, Wu M, Shen F. Surgery for hepatocellular carcinoma presenting with variceal bleeding: The eastern experience. J Surg Oncol. 2016;113(2):165-174.

20 Zheng S, Sun P, Liu X, Li G, Gong W, Liu J. Efficacy and safety of laparoscopic splenectomy and esophagogastric devascularization for portal hypertension: A single-center experience. Medicine (Baltimore). 2018;97(50): e13703

21 Ferraz AA, Bacelar TS, Silveira MJ, et al. Surgical treatment of schistosomal portal hypertension. Int Surg. 2001;86(1):1-8.

22 Silva Neto WBD, Tredicci TM, Coelho FF, Makdissi FF, Herman P. Portal pressure decrease after esophagogastric devascularization and splenectomy in schistosomia. Arq Gastroenterol. 2018;55(2):170174.

23 Lacerda CM, Ramos H, Raia S, Kelner S. Fisiopatologia da hipertensão portal esquistossomótica e efeitos da esplenectomia com ligadura de varizes de esôfago. Acta Cir. Bras. 1993; 8:113-117.

24 de Cleva R, Pugliesi V, Silberstein B, Saad WA, Pinotti HW, Laudanna AA. Systemic hemodynamic changes in mansonic schistosomiasis with portal hypertension with portal hypertension treated by azygoportal disconnection and splenectomy. Am J Gastroenterol. 1999; 94:1632-1637.

25 Chen MS, Li JQ, Liang HH, Lin XJ, Guo RP, Zheng Y, Zhang YQ. Comparison of effects of percutaneous radiofrequency ablation and surgical resection on small hepatocellular carcinoma. Zhonghua Yi Xue Za Zhi. 2005;85(2):80-83.

26 Changyong E, Wang D, Yu Y, Liu H, Ren H, Jiang T. Efficacy comparison of radiofrequency ablation and hepatic resection for hepatocellular carcinoma: A meta-analysis. J Cancer Res Ther. 2017;13(4):625630.

27 Qi X, Zhao Y, Li H, Guo X, Han G. Management of hepatocellular carcinoma: an overview of major findings from meta-analyses. Oncotarget. 2016;7(23):34703-34751.

$28 \mathrm{Ng} \mathrm{KKC}$, Chok KSH, Chan ACY, Cheung TT, Wong TCL, Fung JYY, Yuen J, Poon RTP, Fan ST, Lo CM. Randomized clinical trial of hepatic resection versus radiofrequency ablation for early-stage hepatocellular carcinoma. Br J Surg. 2017;104(13):1775-1784. 
29 Imamura H, Matsuyama Y, Tanaka E, Ohkubo T, Hasegawa K, Miyagawa S, Sugawara Y, Minagawa M, Takayama T, Kawasaki S, Makuuchi M. Risk factors contributing to early and late phase intrahepatic recurrence of hepatocellular carcinoma after hepatectomy. J Hepatol. 2003;38(2):200-207.

30 Wu CJ, Chau GY, Lee IC, Huo TI, Su CW, Hou MC, Huang YH. Early and late recurrence of surgically resected hepatitis $B$ virus-related hepatocellular carcinoma on nucleos(t)ide analogues therapy. $J$ Formos Med Assoc. 2020 Dec 14; S0929-6646(20)30596-9.

31 Lee HW, Lee JM, Yoon JH, Kim YJ, Park JW, Park SJ, Kim SH, Yi NJ, Suh KS. A prospective randomized study comparing radiofrequency ablation and hepatic resection for hepatocellular carcinoma. Ann Surg Treat Res. 2018;94(2):74-82.

32 Chen MS, Li JQ, Zheng Y, Guo RP, Liang HH, Zhang YQ, Lin XJ, Lau WY. A prospective randomized trial comparing percutaneous local ablative therapy and partial hepatectomy for small hepatocellular carcinoma. Ann Surg. 2006;243(3):321-328.

33 Zheng S, Sun P, Liu X, Li G, Gong W, Liu J. Efficacy and safety of laparoscopic splenectomy and esophagogastric devascularization for portal hypertension: A single-center experience. Medicine (Baltimore). 2018;97(50): e13703.

34 Su AP, Zhang ZD, Tian BL, Zhu JQ. Transjugular intrahepatic portosystemic shunt versus open splenectomy and esophagogastric devascularization for portal hypertension with recurrent variceal bleeding. Hepatobiliary Pancreat Dis Int. 2017;16(2):169-175.

35 Takamatsu Y, Hori T, Machimoto T, Hata T, Kadokawa Y, Ito T, Kato S, Yasukawa D, Aisu Y, Kimura Y, Kitano T, Yoshimura T. Intentional Modulation of Portal Venous Pressure by Splenectomy Saves the Patient with Liver Failure and Portal Hypertension After Major Hepatectomy: Is Delayed Splenectomy an Acceptable Therapeutic Option for Secondary Portal Hypertension? Am J Case Rep. 2018; 19:137-144.

36 Fujisaki S, Miyake H, Amano S, Nakayama H, Tomita R, Fukuzawa M. Influence of the extent of hepatectomy on the portal hypertensive state in patients with hepatoma. Hepatogastroenterology. 1999;46(28):2490-2494.

37 Terrault NA, Lok ASF, McMahon BJ, Chang KM, Hwang JP, Jonas MM, Brown RS Jr, Bzowej NH, Wong JB. Update on prevention, diagnosis, and treatment of chronic hepatitis B: AASLD 2018 hepatitis B guidance. Hepatology. 2018;67(4):1560-1599. Fattovich G. Natural history and prognosis of hepatitis B. Semin Liver Dis. 2003;23(1):47-58.

38 Fattovich G. Natural history and prognosis of hepatitis B. Semin Liver Dis . 2003;23(1):47-58.

39 Fattovich G, Pantalena M, Zagni I, Realdi G, Schalm SW, Christensen Erik, European Concerted Action on Viral Hepatitis (EUROHEP). Effect of hepatitis B and C virus infection on the natural history of 
compensated cirrhosis: a cohort study of 297 patients. Am J Gastroenterol.2002;97(11):2886-2895.

40 de Jongh FE, Janssen HL, de Man RA, Hop WC, Schalm SW, van Blankenstein M. Survival and prognostic indicators in hepatitis B surface antigen-positive cirrhosis of the liver. Gastroenterology. 1992;103(5):1630-1635.

41 Fattovich G, Giustina G, Realdi G, Corrocher R, Schalm SW. Long-term outcome of hepatitis B e antigen-positive patients with compensated cirrhosis treated with interferon alfa. Hepatology 1997;26(5):1338-1342.

42 Chinese Society of Infectious Diseases, Chinese Medical Association; Chinese Society of Hepatology, Chinese Medical Association. The guidelines of prevention and treatment for chronic hepatitis B (2019 version). Zhonghua Gan Zang Bing Za Zhi. 2019;20;27(12):938-961.

43 Yin XY, Lai PB, Lee JF, Lau JW. Effects of hepatic blood inflow occlusion on liver regeneration following partial hepatectomy in an experimental model of cirrhosis. Br J Surg. 2000;87(11):1510-1515.

\section{Table}

Table 1. Baseline characters of cirrhotic patients performed with RFA or hepatectomy combined with PCDV plus splenectomy for HCC patients with EVB 


\begin{tabular}{|c|c|c|c|}
\hline variables & RFA group & Hepatectomy group & $P$-value \\
\hline Age(years) & $50.15 \pm 9.26$ & $50.73 \pm 7.98$ & 0.563 \\
\hline Sex male/female & $17 / 3$ & $21 / 5$ & \\
\hline Etiology, HBV/HCV/other & $18 / 1 / 1$ & $20 / 2 / 4$ & \\
\hline largest dimension of spleen $(\mathrm{cm})$ & $25 \square 25-27 \square$ & $22 \square 20-30 \square$ & 0.322 \\
\hline $\mathrm{AFP}(\mathrm{ng} / \mathrm{ml})$ & 2.65ロ1.50-10.83凸 & $6.60 \square 2.90-37.80 \square$ & 0.026 \\
\hline WBC count $(\times 109 / \mathrm{L})$ & $2.23 \pm 0.63$ & $3.19 \pm 1.77$ & 0.004 \\
\hline PLT count $(\times 109 / \mathrm{L})$ & $47.49 \pm 18.15$ & $49.57 \pm 17.71$ & 0.663 \\
\hline $\mathrm{RBC}(\times 1012 / \mathrm{L})$ & $3.91 \pm 0.77$ & $3.66 \pm 0.80$ & 0.685 \\
\hline HGB $(g / L)$ & $110.96 \pm 24.19$ & $108.63 \pm 26.82$ & 0.941 \\
\hline ALT (U/L) & $24.70 \pm 14.82$ & $23.19 \pm 7.71$ & 0.015 \\
\hline AST (U/L) & $28.46 \pm 18.41$ & $6.92 \pm 1.36$ & 0.035 \\
\hline TBIL $(\mu \mathrm{mol} / \mathrm{L})$ & $19.72 \pm 10.97$ & $20.13 \pm 9.73$ & 0.698 \\
\hline $\mathrm{ALB}(\mathrm{g} / \mathrm{L})$ & $37.07 \pm 5.67$ & $37.05 \pm 4.84$ & 0.540 \\
\hline CHE (U/L) & $4344.95 \pm 1317.06$ & $4015.81 \pm 1461.70$ & 0.631 \\
\hline $\mathrm{Cr}(\mu \mathrm{mol} / \mathrm{L})$ & $64.59 \pm 14.84$ & $68.38 \pm 13.90$ & 0.545 \\
\hline PT (s) & $13.67 \pm 1.12$ & $14.40 \pm 1.91$ & 0.031 \\
\hline INR & $1.16 \pm 0.11$ & $1.25 \pm 0.21$ & 0.019 \\
\hline Operation time (minutes) & $337.25 \pm 110.10$ & $277.31 \pm 85.51$ & 0.259 \\
\hline *Intraoperative blood loss (ml) & $100.00 \pm 220.00$ & $230.00 \pm 426.00$ & 0.010 \\
\hline *Intraoperative blood transfusion, no/yes & $18 / 2$ & $19 / 7$ & 0.007 \\
\hline Tumor number, solitary/multiple & $20 / 1$ & $20 / 6$ & 0.091 \\
\hline Tumor size $(\mathrm{cm})$ & $2.20 \pm 0.98$ & $3.18 \pm 1.37$ & 0.080 \\
\hline \multicolumn{4}{|l|}{ Histology(differentiated) } \\
\hline Well/Moderately/Poorly & $8 / 10 / 2$ & $8 / 13 / 5$ & 0.634 \\
\hline \multicolumn{4}{|l|}{ Varices stage, small/middle/large } \\
\hline \multirow[t]{2}{*}{ ECOG, $0 / 1$} & $0 / 4 / 16$ & $6 / 9 / 11$ & 0.017 \\
\hline & $19 / 1$ & $24 / 2$ & \\
\hline Child's score & $4.05 \pm 1.15$ & $4.23 \pm 1.21$ & 0.396 \\
\hline Child-Pugh stage, A/B & $19 / 1$ & $25 / 1$ & 0.849 \\
\hline ALBI & $-2.34 \pm 0.52$ & $-2.32 \pm 0.43$ & 0.307 \\
\hline ALBI stage, $1 / 2 / 3$ & $8 / 11 / 1$ & $6 / 19 / 1$ & 0.435 \\
\hline BCLC stage, A/B & $20 / 0$ & $26 / 0$ & \\
\hline
\end{tabular}

Note: Data accorded with normal distribution was expressed in mean \pm standard deviation. Data not accorded with normal distribution was expressed in median with interquartile range.

\section{Figures}



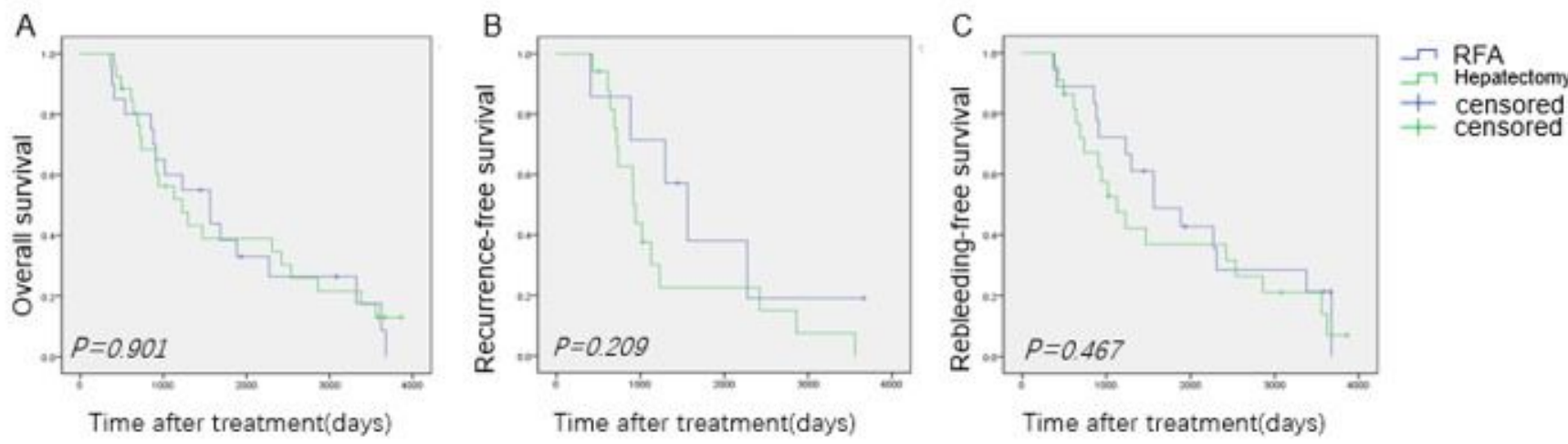

+ censored

+ censored

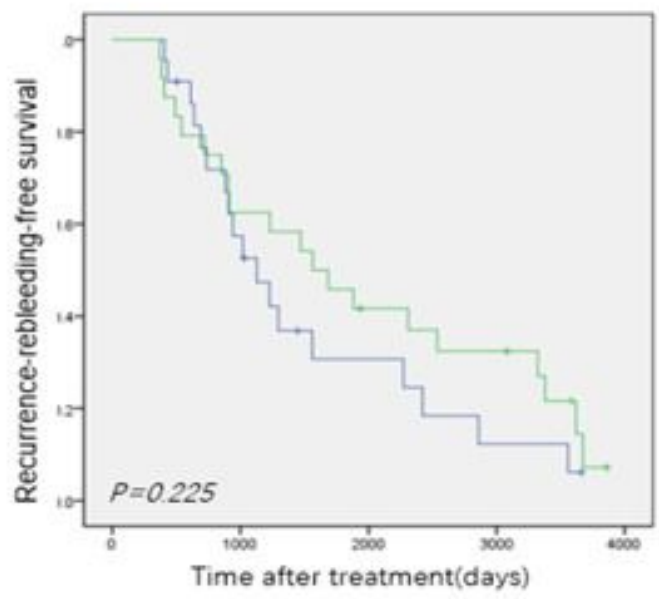

$\neg$ RFA

IT hepatectomy

+ censored

+ censored

\section{Figure 1}

A. Overall survival for the cirrhotic HCC patients with EVB who performed with RFA or Hepatectomy combined with PCDV. There were no significant differences between the hepatectomy and RFA groups $(P=0.901)$. B. Recurrence free survival for the cirrhotic HCC patients with EVB who performed with RFA or Hepatectomy combined with PCDV. There were no significant differences between the hepatectomy and RFA groups $(P=0.209)$. C. Rebleeding free survival for the cirrhotic HCC patients with EVB who performed with RFA or Hepatectomy combined with PCDV. There were no significant differences between the hepatectomy and RFA groups $(P=0.467)$. $D$. Recurrence-rebleeding free survival for the cirrhotic HCC patients with EVB who performed with RFA or Hepatectomy combined with PCDV. There were no significant differences between the hepatectomy and RFA groups $(P=0.225)$. 